\title{
COORDENADAS DEL VIDEO AUTOBIOGRÁFICO! EL RELATO DE LA EXPERIENCIA DE VIDA MEDIADA, MEDIÁTICA Y MEDIATIZADA
}

DIEGO LEANDRO MARÍN OSSA

Universidad Tecnológica de Pereira

RESUMEN En este artículo se plantea un marco general del video autobiográfico y la experiencia de vida mediatizada, para ello se hacen distinciones, se señalan límites y posibilidades, pero sobre todo se establecen relaciones entre los actos de ver y mirar, los actos de relatar, narrar y contar, las nociones de historia (story) y de Historia (history), en la antigua discusión entre lo que es mito y lo que es logos, lo que es verdad, falsedad, mentira y realidad. También se plantea la idea de medio más allá del contexto comunicativo, y se ubica la discusión en los contextos formativos e investigativos, para ello se plantea que medio es algo que está entre dos elementos: en la mitad de una relación que puede ser entre el emisor y el receptor, el profesor y el estudiante, el sujeto que conoce y el objeto de su conocimiento. Luego se hacen distinciones entre videoautobiografia y video autobiográfico, y se plantean ideas de cómo estas dos formas de pensamiento videográfico aportan a la construcción de la conciencia de sí, al yo histórico reflexivo y se expresan en las coordenadas espacio temporales en las que se representa el yo. Además se plantea una definición de autobiografía en la que en lugar de hablar de autor y narrador, se habla de autobiógrafo que es quien adquiere y desarrolla las habilidades y la conciencia de sí, por medio del relatar y el reflexionar lo vivido, lo recordado y lo relatado. Para finalizar se exponen ideas en relación con la experiencia mediatizada desde el aprendizaje, los medios de comunicación, la sociología, y el lenguaje. A lo largo del texto se plantea una reflexión a cerca de si la interacción con las pantallas y las imágenes modifican nuestra mirada, nuestro pensamiento y nuestra existencia.

1 El artículo es fruto de una reflexión sobre el video, el relato autobiográfico y la experiencia de vida mediatizada, y hace parte de un proceso que inicié con mi producción videográfica en el año 2003, la investigación que emprendí en el año 2007 y las publicaciones y ponencias realizadas en los CIPA de 2014 y 2016 . También está relacionado con una de las líneas del grupo y semillero de investigación Edumedia-3 que inició labores en el año 2013 y que dirijo en la Universidad Tecnológica de Pereira, y con el proceso de tesis doctoral que vengo realizando desde 2016 con el Gabinete de Comunicación y educación, en el Doctorado de Comunicación y Periodismo de la Universidad Autónoma de Barcelona, donde estoy indagando El relato (auto)biográfico como método para el desarrollo de habilidades (auto)expresivas y (auto)reflexivas de la competencia mediática, bajo la dirección de José Manuel Pérez Tornero. 
Palabras claves: Video autobiográfico. Relato autobiográfico. Experiencia de vida mediatizada. Mediación (auto)biográfica. Autobiógrafo.

\section{THE STORY OF THE MEDIATED, MEDIATIC AND MEDIATIZED LIFE EXPERIENCE}

In this article a general framework of the autobiographical video and the experience of mediated life is proposed. For this, distinctions are made, limits and possibilities are pointed out, but above all, relationships are established between the acts of seeing and looking, the acts of reporting, narrating and telling, the notions of story and history, in the old case discussion between what is myth and what is logos, what is true, falsehood, lie and reality. The idea of means beyond the communicative context is also raised, and the discussion is located in the formative and investigative contexts, for which it is proposed that the medium is something that is between two elements: in the middle of a relationship that can be between the sender and the receiver, the teacher and the student, the subject who knows and the object of their knowledge. Then, distinctions are made between video-autobiography and autobiographical video, and ideas on how these two forms of videographic thought contribute to the construction of self-consciousness, to the reflective historical self and are expressed in the temporal space coordinates in which the self is presented. In addition, a definition of autobiography is proposed in which instead of talking about author and narrator, we speak of an autobiographer who is the one who acquires and develops the skills and self-awareness, through the narration and reflection of what has been lived, recalled and reported. Finally, ideas are presented in relation to the mediatized experience from the points of view of learning, the media, sociology, and language. Throughout the text a reflection is raised about whether the interaction with screens and images modifies our view, our thinking and our existence.

Keywords: Autobiographical video. Autobiographical story. Mediatized life-experience. (Auto)biographical mediation. Autobiographer. MEDIÁTICA E MEDIATIZADA

Neste artigo, propõe-se um quadro geral do vídeo autobiográfico e da experiência de vida mediatizada. Para tal efeito, fazem-se distinções, apontam-se limites e possibilidades, mas, acima de tudo, 
se estabelecem relações entre os atos de ver e olhar, os atos de relatar, narrar e contar, as noções de estória (story) e História (history), na antiga discussão entre o que é mito e o que é logos, o que é verdadeiro, a falsidade, a mentira e a realidade. Propõe-se assim mesmo a ideia de meio além do contexto comunicativo, e localiza-se a discussão nos contextos formativos e investigativos, para o qual se propõe que meio seja algo que está entre dois elementos: no meio de uma relação que pode ser entre o remetente e o receptor, entre o professor e o aluno, entre o sujeito que conhece e o objeto de seu conhecimento. Seguidamente, fazem-se distinções entre vídeoautobiografia e vídeo autobiográfico, e propõem-se ideias sobre como essas duas formas de pensamento videográfico contribuem para a construção da autoconsciência, para o Eu histórico reflexivo e são expressas nas coordenadas espaciais-temporais nas quais o Eu é apresentado. Além disso, propõe-se uma definição de autobiografia em que, em vez de falar sobre autor e narrador, fala-se em autobiógrafo que é aquele que adquire e desenvolve habilidades e autoconsciência, através da narração e a reflexão sobre o que foi vivido, lembrado e relatado. Finalmente, propõem-se ideias em relação à experiência mediatizada desde a aprendizagem, a mídia, a sociologia e a linguagem. Ao longo do texto propõe-se uma reflexão respeito de se a interação com as telas e as imagens modificam o nosso olhar, o nosso pensamento e a nossa existência.

Palavras-chave: Vídeo autobiográfico. Relato autobiográfico. Experiência de vida mediatizada. Mediação (auto)biográfica. Autobiógrafo.

\section{Introducción}

La palabra video viene del latín videre que significa yo veo, pero ¿es lo mismo ver que mirar?, si ver y mirar son actos biológicos y culturales, cognitivos y simbólicos que están íntimamente ligados a nuestras vidas, entonces ¿medios de comunicación audiovisual como el cine, la televisión y el video han modificado nuestra experiencia de vida?, ¿es posible conocer las maneras como se transforman nuestra mirada, nuestro pensamiento y nuestra existencia en interacción con las imágenes y las pantallas?

Para aproximarnos a algunas de las respuestas es útil abordar las pesquisas que nos propongamos a partir de la autobiografía en la educación, ${ }^{2}$ el método biográfico narrativo ${ }^{3}$ y la (auto)biografía en formación, ${ }^{4}$ en función de

2 El método explicado por José González Monteagudo (2010), es muy claro en su texto La autobiografía educativa: formación, investigación y profesionalidad reflexiva.

3 Considero que la explicación de Antonio Bolivar (2002), es clara y útil. Se puede consultar en su artículo Metodología de la investigación biográfico-narrativa: recogida y análisis de datos.

4 El desarrollo de este método tiene orígenes en los años 80, pero en el CIPA Congresso Internacional de Pesquisa (Auto)biográfica ha tenido una amplia difusión a nivel mundial y se han generado publicaciones muy interesantes en la colección que se edita en cada congreso, la Associação Brasileira de Pesquisa (Auto) Biográfica (BIOgraph) es la principal promotora de este movimiento científico y académico. Para obtener más información al respecto se puede visitar la página http://www.biograph.org.br 
nuestra experiencia de vida con los medios de comunicación, las imágenes y las pantallas. ${ }^{5}$

Una autobiografía de los medios en nuestras vidas aportaría elementos valiosos para abordar estas cuestiones, establecer distinciones y relaciones conceptuales, metodológicas, éticas y estéticas variadas, ricas y complejas. ${ }^{6}$

Aquí haré algunas distinciones y estableceré relaciones entre términos y conceptos, para contribuir a la discusión sobre video, relato, autobiografía y experiencia de vida mediatizada.

\section{Ver y mirar}

Desde un punto de vista se puede decir que la visión es biológica y la mirada es cultural, así una persona que carezca del sentido de la vista puede tener una mirada de su vida y del mundo, aprendida por canales táctiles, orales y auditivos, por medios como el habla, el cuer-

5 Esta reflexión hace parte del proceso de investigación que emprendí en el año 2016, cuando inicié el Doctorado en Comunicación y Periodismo, con el Gabinete de Comunicación y Educación en la Universidad Autónoma de Barcelona. El proyecto se está desarrollando en tres universidades: Universidad Tecnológica de Pereira-Colombia, Universidad de São Paulo-Brasil y Universidad Autónoma de Barcelona-España, titula El relato (auto)biográfico como método para introducir a los estudiantes en el desarrollo de habilidades (auto) reflexivas y (auto)expresivas de la competencia mediática bajo la dirección de José Manuel Pérez Tornero. En diciembre tuve la oportunidad de compartir una semana de actividades formativas e investigativas en la Universidade do Estado do Rio de Janeiro, con los grupos de pesquisa Polifonía y Vozes da educação lo cual me dejó varios interrogantes que ahora abordo en este texto, gracias a las inquietudes que recogí de las investigadoras coordinadas por Inês Bragança.

6 Si bien es cierto que David Buckingham (2003), y otros han realizado algunas de las investigaciones en ese sentido desde la perspectiva de la Educación mediática, se requieren también las investigaciones con enfoques antropológicos y existenciales como complemento y articulación a los de corte semiótico y mediático. Sobre el autor se puede consultar el libro de su autoría, Educación en medios, en el que expone algunos asuntos de su experiencia en el sentido mencionado.

7 El profesor colombiano Fernando Vásquez Rodríguez escribió un bello ensayo titulado: Más allá del ver está el mirar. Pistas para una semiótica de la mirada, en el que explora con acertados ejemplos esta y otras distinciones. po, la escucha y sistemas de lectura y escritura como el Braille.

Pero no todas las personas que poseen el sentido de la vista y los otros sentidos, desarrollan una mirada del mundo lo suficientemente amplia para enfrentar los avatares del tiempo y de la historia incluida la de su propia vida.

Se pueden ver cosas y personas moverse o en su aparente quietud, cosas y personas que hacen ruido o parecen mudas, se pueden ver la luz y la sombra sin caer en la cuenta de que son parte de fenómenos como el ciclo del día y de la noche o la proyección de cosas y personas, de caras ocultas a la fuente luminosa.

También se pueden ver los ojos de otras personas sin experimentar mucha curiosidad por la sutileza de los cambios en el brillo y el tamaño de la pupila a lo largo de una conversación. "El ver busca cosas; el mirar, sentidos. $Y$ si las ciencias naturales han mejorado las limitaciones de nuestro ver, son las ciencias de la cultura las que han conquistado y legitimado las diversas formas de mirar." (VÁSQUEZ, 1992, p. 32).

Mirar requiere otra disposición. A mirar se enseña y se aprende. Ver corresponde a los mecanismos biológicos que posibilitan la supervivencia, mirar permite elaborar nuestras versiones y nuestras visiones de mundo y de existencia.

El ver es natural, inmediato, indeterminado, sin intención; el mirar, en cambio, es cultural, mediato, determinado, intencional. Con el ver se nace; el mirar hay que aprenderlo. El ver depende del ángulo de visión de nuestros ojos, el mirar está en directa relación con nuestra forma de socialización, con la calidad de nuestros imaginarios, con todas las posibilidades de nuestra memoria. (Ibid, p. 32).

Para ello de la socialización desde temprana edad, ${ }^{8}$ se obtienen elementos y de la cul-

8 Jerome Bruner (2013), junto a otros colegas suyos hizo estudios en este sentido que demuestran cómo 
tura también: experiencias, signos, anécdotas, lenguajes, medios, una cantidad de recursos que hacen posible la elaboración de maneras de comunicarse entre sí mismo y el mundo, adquiriendo y compartiendo una serie de inventarios que dicen mucho de las personas: tradiciones, recuerdos, memorias, amores y desamores conservados en cartas, mensajes, álbumes fotográficos, videos caseros, diarios, objetos, canciones, poemas, huellas en la piel, imágenes de sí mismo en redes sociales, blogs y páginas personales, ombligos y hasta epitafios que anticipan el último deseo de alguien para que sea cumplido después de su muerte. Los lenguajes para la vida y la creación, ${ }^{9}$ se funden en lenguajes para la supervivencia y para la existencia.

Se puede ver y se puede aprender a mirar, como también se puede ver a través de un visor y un lente y tomar fotografias, se puede filmar una película o se puede grabar un video, pero el solo registro de imágenes y sonidos no hace de un archivo audiovisual un relato, al menos no intencionado pues así como se aprende a mirar también se aprende a relatar. La visión a través de visores, lentes y pantallas podría denotar el dominio instrumental de una tecnología y sus interfaces, pero mirar implica adquirir y desarrollar visión de mundo.

La autobiografía con medios ayuda a esto pues desarrolla la mirada retrospectiva y en perspectiva, de una manera articulada al pensamiento audiovisual, nos permite usar filtros, cámara rápida y lenta, disolvencias, encua-

se elabora el Yo narrativo, por ejemplo en un análisis que hace junto a la doctora Joan Lucariello, de los soliloquios de Emmy grabados por sus padres cuando está dormida. En el artículo La invención del yo: la autobiografia y sus formas se explica en detalle el estudio.

9 El maestro Francisco Cajiao (1997), hace una bella reflexión sobre esto en su texto Cosas, signos y lenguajes publicado en la revista La alegría de enseñar Año 7 No.32 (Jul.-Sep.1997), en el que habla de los lenguajes para la vida y los lenguajes para crear, yo considero que también son lenguajes para la supervivencia y para la existencia. dres, ángulos y movimientos de cámara en los procesos de recordación, como expresión de nuestro álbum fotográfico personal, de nuestro archivo de video casero, formas sonoras y visuales de nuestra memoria autobiográfica. Nuestras imágenes mentales ahora son la connotación de las imágenes audiovisuales con las que elaboramos nuestra experiencia de vida mediatizada. ${ }^{10}$

Un video casero puede decirnos muchas cosas de las personas que aparecen allí y podemos ver en este registro mucho más de lo que quiso transmitir la persona que lo grabó. Esas interpretaciones tienen múltiples posibilidades y también tienen sus límites.

Pero no es la cámara la que toma bellas fotos, o filma o graba, es el que mira quien impacta y deja en nuestra memoria visual los episodios y acontecimientos que llevamos con nosotros por largo tiempo, y para ello puede usar una cámara básica o de última generación, porque lo importante es qué se relata y cómo se relata más que los artefactos que se usan para ello.

Por estas razones en los estudios de medios de comunicación se habla de punto de vista óptico (encuadres, planos, ángulos...), y se habla de punto de vista narrativo (narrador, estructura narrativa...), los cuales se pueden identificar a partir de la manera como un relato está hecho por medio del lenguaje audiovisual y desde donde miran y narran el cineasta, el productor y el videasta. Un análisis del discurso y del contenido ya sea estructural, semiótico, antropológico, o de cualquier otro enfoque permite identificar estos y otros aspectos.

Pero solo una observación y una reflexión amplia permite descubrir de qué manera el punto de vista óptico y el punto de vita na-

10 John B. Thompson (2010), plantea una serie de cuestiones al respecto, he incluso distingue modos de experiencia en función de los medios, en su obra Los medios y la modernidad. Mas adelante trataré el tema con otros autores que entienden diferentes cosas cuando hablar de mediatizar. 
rrativo, representan las coordenadas espacio temporales del yo.

\section{Relatar, narrar, contar}

Desde el punto de vista del pensamiento moderno se pude decir que en la Antigüedad la mitología representó la cosmovisión de los pueblos, sus relatos de fundación, de origen y de transición entre otros, cumplieron funciones organizativas y cohesionadoras. Aun hoy las mitologías contemporáneas y también de pueblos que conservan este acervo cultural organizan de manera simbólica su mundo a partir de relatos.

La historia de la división entre mitos y logos en los orígenes de las Ciencias Naturales y las Humanidades, tomó un largo camino y eternas discusiones alrededor del carácter objetivo y subjetivo, verídico y falso de lo relatado, y se generaron varias soluciones prácticas en diversos contextos. ${ }^{11}$

Así las Ciencias Naturales se asociaron a las ideas de verdad, de conocimiento y realidad, y solo con el tiempo las Ciencias Sociales y las Humanidades se asociaron con los mismos conceptos, con marcos de referencia diferentes y en ocasiones complementarios que no entraré a detallar para seguir el rumbo que tomé desde el comienzo en el artículo.

Pero si quiero plantear que al hablar de mito este se asocia con un relato, pero también con la ficción, con la invención de situaciones protagonizadas por personajes en un cronotopo o espacio-tiempo determinado, incluso se asocia con mentira que no es lo mismo que falsedad lo que es opuesto a la verdad.

De allí que se considere que el cine a la literatura ofrecen otros caminos a la verdad y al conocimiento diferentes a los que ofrecen las Ciencias.

11 Me gusta la reflexión que plantean los autores del monográfico titulado Las voces del tiempo, compilación de Fabio Silva Vallejo (1999).
Así las cosas, tenemos los relatos de las Ciencias Naturales y Sociales, los relatos de las humanidades e incluso los relatos de la educación y de las religiones que, desde una perspectiva hermenéutica, semiótica y antropológica, representan conocimientos y verdades de diversa naturaleza.

Ahora bien, cuando se habla de narración y esta se asocia con el acto de narrar sea de manera oral o escrita, y en ese sentido se puede decir que un relato se narra al lado de una hoguera acompañado de oyentes ubicados en círculo, o como ocurre en la literatura por medio de la escritura dirigida a los lectores, o en el cine en la pantalla con espectadores frente a ella, pero además de que existen otros medios y otras formas en la experiencia de la recepción, cabe preguntarse hasta que punto cuando se trata de la difusión de la Ciencia los científicos actúan como narradores para usar los relatos como analogías de sus indagaciones, de su comprensión y de sus explicaciones, hasta que punto hacemos lo mismo los educadores e incluso los historiadores, ¿qué dimensiones de la subjetividad y de la ficción permean los relatos de la objetividad?

Cabe también preguntarse si todo relato se narra, si existe narrador y estructura narrativa, si hay una historia que contar. En las artes escénicas, la literatura y el video no siempre es así, a veces se usa el narrador y el diálogo, las escenas y demás recursos narrativos para representar algo, pero otras veces se privilegia la función performativa del lenguaje, y se da lugar al pastiche, al palimpsesto, al collage, a las mezclas o mixturas, a la experimentación y el remix y se funden géneros, formatos, artes, medios, imágenes, recursos de diversa fuente y naturaleza expresiva que las vanguardias del arte y de los medios en Rusia, Europa y Estados Unidos exploraron hasta la saciedad.

De otra parte hay que decir que se cuentan números y se cuentan historias sólo que en el 
primero se da importancia a las cuentas y en el segundo a los cuentos, y así como narrar es un acto al cual la especie humana ha aportado complejos sistemas y recursos para hacerlo un acto novedoso y atractivo, contar es un acto no menos importante y en ocasiones requiere la capacidad de síntesis, de encadenamiento y de organización de eventos y descripción de situaciones elaboradas de manera fina y eficaz.

Puede ser que el contar esté subordinado a la narración o sea su complemento. En español se asocia el cuento con el acto de contar, y el narrar con la narración, las dos acciones pueden ser de manera oral o escrita, sólo que en medios como el cine el cuento toma formas narrativas que incluso pueden seriadas y capituladas por episodios que permitan comunicar la historia que subyace, ocurre algo similar en la televisión, solo que en ocasiones el cuento se puede contar a manera de testimonio como ocurre en programas de reportaje o en algunos documentales.

En ese orden de ideas en algunas lenguas como en el inglés, Historia en singular y con mayúscula se escribe history, es pues la Historia de los hechos incontrovertibles acontecidos y registrados de alguna manera y por algún medio, y la historia, inventada, ficticia, se escribe story aunque en algún porcentaje sea producto de la anterior como ocurre en la novela histórica, en el docudrama o en la ficción histórica utilizada en el teatro, el cine y en la televisión.

En cambio en español no existe esa distinción formal que influye en el sentido y el significado, y para ello cuando se habla de la historia que se aborda en una novela o en una película, para distinguirla de la Historia contada por los historiadores, se espera que los receptores interpreten lo que se dice según el contexto de emisión y de recepción.

Entre relatar, narrar y contar no existen diferencias marcadas y tal vez no sean necesa- rias, a menos que se trate de categorías de investigación que requieran de ello por razones tanto teóricas, como prácticas y metodológicas. Para ello los estudios literarios y mediáticos, han resuelto relaciones y distinciones útiles en esos casos, como también se hace con las palabras discurso e historia.

En mi caso prefiero hablar de relato, pues más allá de consideraciones filológicas, gramaticales y semánticas, la dimensión semiótica, antropológica y existencial de esta idea, permite corroborar que el relato si bien requiere de los lenguajes para cumplir sus funciones representativa y cognitiva, para cumplir con su finalidad comunicativa no siempre recurrimos a la narración, ni siempre los contamos pues algunos son eventos performativos, a veces son tan abstractos que prescinden de esas categorías.

\section{Medios de comunicación audiovisual y videoclip}

Un medio es algo que está entre dos elementos: en la mitad de una relación que puede ser entre el emisor y el receptor, el profesor y el estudiante, el sujeto que conoce y el objeto de su conocimiento.

Figura 1 - El medio como tercero entre dos cosas

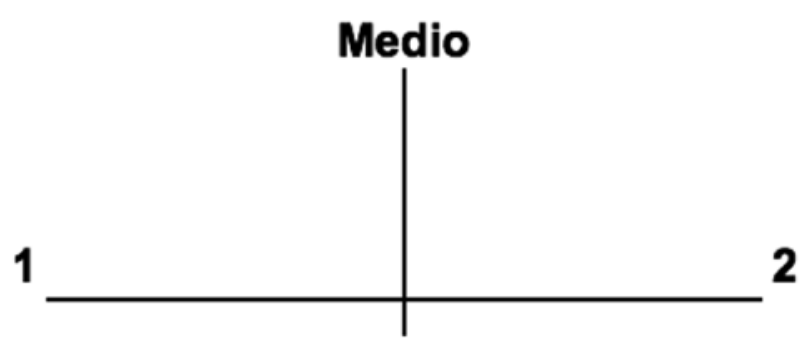

Fuente: Elaboración propia.

Pero cuando se habla de medios de comunicación vemos que la especie humana ha inventado maneras de comunicarse en diferentes momentos, para lo cual disciplinas como la arqueología nos han demostrado que el cuer- 
po, la palabra y la imagen han sido protagonistas en este sentido, lo que se puede constatar en el arte rupestre, en los soportes usados por diferentes culturas y que van desde la piel de animales y de los mismos humanos, arcilla, la madera, la piedra, el metal, el vidrio, el papel.

Sabemos que los medios de comunicación en la modernidad son el cartel, el cómic, la prensa, la radio, la fotografia, el cine, la televisión, el video, el ordenador y los dispositivos móviles. Y que los intercambios de géneros, lenguajes, contenidos, formatos, y otros aspectos como las audiencias, hacen parte del ecosistema mediático.

Y llamamos TIC a muchos de estos medios y a otros más nuevos como las redes sociales, sobre todo para poner el énfasis en la manera como las tecnologías de la información y de la comunicación están transformándolo todo, dando lugar a muchos fenómenos, entre ellos a la aplicación de conocimiento científico en el abordaje de cuestiones como por ejemplo las educativas.

Es aquí donde se ubica el paradigma autobiográfico en la educación, pues se considera que tanto los estudiantes como los profesores, los emisores como los receptores hacen parte de un mismo fenómeno: la vida como objeto de conocimiento en la que están inmersos los sujetos, como protagonistas y espectadores de su devenir en el mundo, como relatores y personajes de sus relatos en primera persona.

Figura 2 - El paradigma autobiográfico en medio del proceso formativo, investigativo y comunicativo

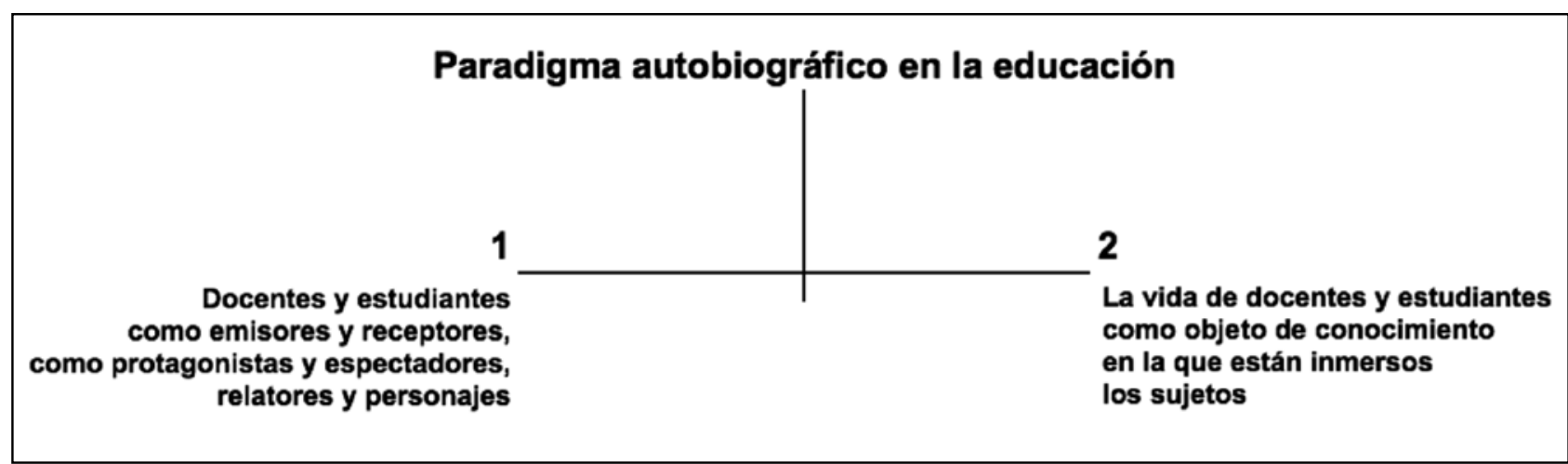

Fuente: Elaboración propia.

En este paradigma el relato autobiográfico se puede adaptar a cualquier medio, pero habrá que elegirlo según los objetivos que se tengan en la investigación y en la formación, pues la naturaleza expresiva de cada medio hace del relatar algo excepcional.

Ahora bien, cuando se habla de medios de comunicación audiovisual, desde un punto de vista se entiende que estos requieren de nuestros canales visuales y auditivos para cumplir su función, en ese sentido el cuerpo y la voz hacen parte de ellos, y continúan presentes en todos los medios de diferente manera, algo que se puede observar en el cine, la televisión y el video pese a sus continuas transformaciones e hibridaciones.

De hecho los medios de comunicación audiovisual hacen parte de la historia de la visión y de la mirada en las Ciencias Naturales, las Ciencias Sociales y las Humanidades en múltiples dimensiones que van más allá de su concepción instrumental.

$Y$ puede que compartan algunas características pero son diferentes pues cada medio se puede comprender y explicar de maneras distintas en función de su naturaleza expresiva, de sus usos y de los contextos sociales y culturales en que emergió cada uno, e impacta 
en quienes los usamos, nuestra sensibilidad y la manera que tenemos de relacionarnos por medio de ellos con el mundo.

En el video por ejemplo se pueden distinguir numerosas formas de relatar, ${ }^{12}$ una de ellas es el videoclip que tomó elementos de medios como el cine, se insertó en la televisión, en las artes visuales y en la antropología visual, y navega por la web en muchas formas.

Su plasticidad, su flexibilidad y sus facilidades de difusión permiten explorar recursos visuales y sonoros que provienen de variadas fuentes, como ocurre en los videoclip musicales que se producen y se intercambian a diario.

Con un videoclip musical como Do the evolution de Pearl Jam podemos analizar en la forma y en el contenido, varias capas de la complejidad y riqueza conceptual y expresiva de su elaboración, desde los puntos de vista estético, ético-político, social, económico y cultural, ${ }^{13}$ como si se tratara de un ejercicio de exégesis. Pero ¿Qué ocurre cuando estudiantes y docentes pasan de ser espectadores a protagonistas de su historia de vida en un videoclip autobiográfico?

\section{Videoautobiografía y video autobiográfico}

Hablar de videoautobiografía es legitimar la idea de que la autobiografía ha encontrado otro medio además de los que ya existen como por ejemplo el libro y la escritura, o la voz y la oralidad. Se agrega entonces un prefijo: video que como dije al comienzo significa yo veo.

Y me da la impresión que aquí se trata de poner énfasis en el medio como instrumento que sirve para registrar, documentar o guardar

12 Omar Rincón (2006), ha dedicado un capítulo a las narrativas y las formas del video en su libro Narrativas Mediáticas. O cómo se cuenta la sociedad del entretenimiento. Quizá es uno de los pocos textos que en español confieren un estatus de autonomía al video.

13 En el año 2013 dirigí una trabajo de grado en el que sugerí el videoclip mencionado a las estudiantes que plantearon una manera de usar el videoclip musical en las Ciencias Sociales. memoria de un relato oral, un testimonio personal que alguien cuenta sobre sí mismo ante la cámara de video sin importar demasiado si es otro el que maneja la cámara y edita.

Y eso lo hacen investigadores como los psicólogos o los antropólogos, los segundos saben que medios como el video se usan para documentar procesos, como medio para archivar información, pero también como resultado o producto de la investigación. ${ }^{14}$

En ese sentido el video es instrumento, medio técnico, soporte de memoria audiovisual y aunque los investigadores en ocasiones le dan la cámara a las personas o grupos que son objeto y sujeto de sus indagaciones, el uso de este recurso es más escaso debido a lo complejo y extenso que se vuelve un proceso, que requiere incluso capacitar a personas que en ocasiones no tienen idea del uso del medio para que luego hagan sus propios relatos.

De otra parte las palabras videoautobiografia y autobiografia son sustantivos, nombres que desplegados en el sintagma, en la línea temporal y espacial de idiomas como el español, el portugués, el francés (autobiographie), el inglés (autobiography) y otros, sugieren una relación entre el lenguaje como expresión de nuestra conciencia de sí y las coordenadas espacio temporales en las que nos representamos cuando narramos nuestra vida.

Cabe recordar que la obra de Ferdinand De Saussure (1945), plantea la relación sintagma/ paradigma no sólo como una de sus clásicas dicotomías, si no además como uno de los referentes teóricos que ahora sirve para comprender el lenguaje como representación de nuestras concepciones de tiempo pasado, presente y futuro y las dimensiones del espacio en las que también se expresan nuestra experiencia y nuestra existencia.

14 Las investigaciones y textos de Elisenda Ardèvol (1998), de Carmelo Pinto (1999), o Bill Nichols (1997), dan cuenta de estos y otros usos del video entre otros medios de la antropología visual y audiovisual. 
Figura 3 - Relación sintagma/paradigma en relación con la autobiografía

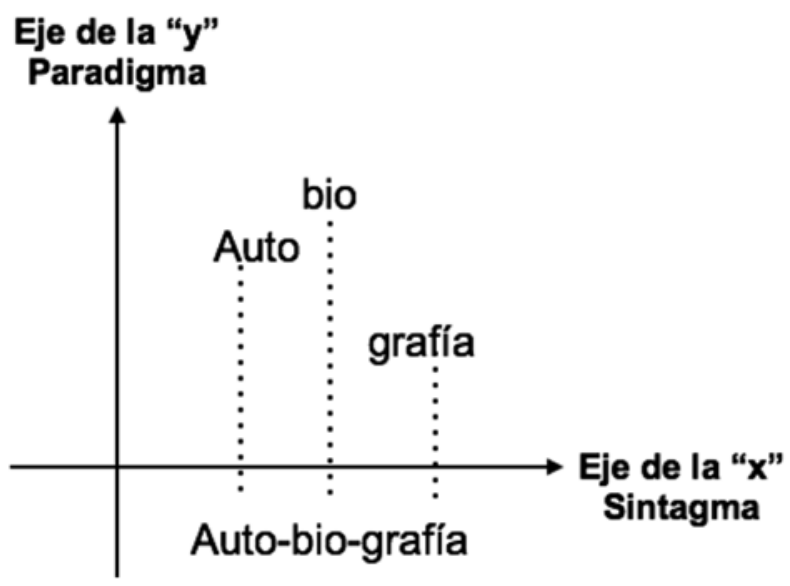

Fuente: Elaboración propia, basado en el Curso de Lingüística General de Ferdinand De Saussure

Jerome Bruner (2010), considera el plano de la narración (eje de la " $x$ "), como una de las modalidades de pensamiento o de cómo organizamos nuestras ideas, mientras que el plano de la argumentación (eje de la "y"), es otra de las modalidades de pensamiento, diferente a la anterior y a la vez su complemento.

Por su parte Antonio Bolivar (2012), tiene en cuenta la teoría de Bruner (Ibid), para explicar parte de la metodología del enfoque biográfico narrativo, y se puede decir que en el plano de la argumentación se organiza todo aquello que implique los argumentos que aportan los (auto)biógrafos en el proceso, por medio de discusiones, entrevistas, cuestionarios, y en el plano de la narración estarían las autobiografías incluida la del docente investigador principal, obtenidas también en el mismo proceso.

Ahora bien, es sabido que cuando se graba o cuando se edita video, el proceso de montaje que inicia con la concepción de la idea autobiográfica hasta el momento en que todo está listo para renderizar, ${ }^{15}$ no está al margen de estas coordenadas.

15 La palabra hace parte de la jerga de la informática y significa la generación de una imagen realista de modelos 3D, por medio del cálculo de información obtenida de los clips de audio e imagen, a través del software de edición, en el que se "mezclan" y se "funden" sonidos, imágenes, efectos, música, transiciones, títulos y demás elementos del lenguaje audiovisual.
Figura 4 - Relación sintagma/paradigma en relación con los dos modos de pensamiento: argumentación y narración propuestos por Jerome Bruner.

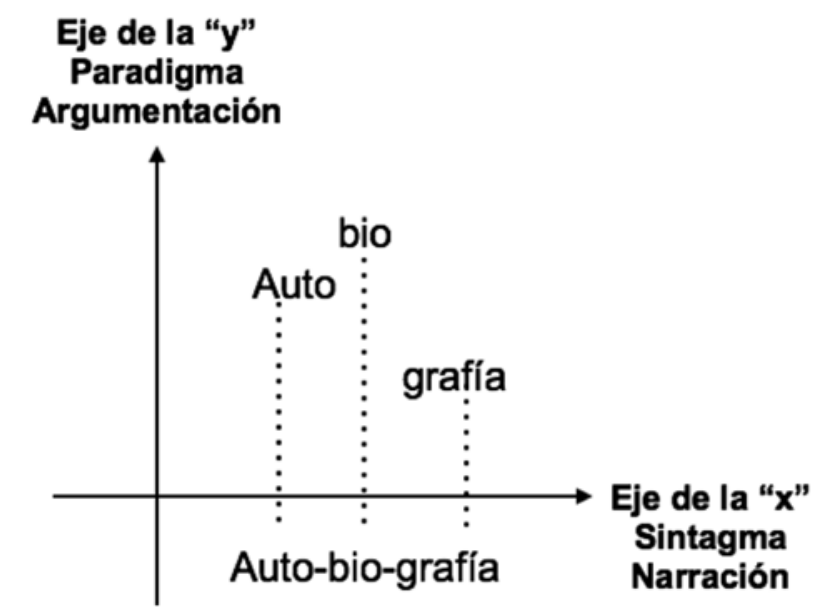

Fuente: Elaboración propia basado en el Curso de Lingüística General de Ferdinand De Saussure y en Realidad Mental y Mundos Posibles de Jerome Bruner.

En ocasiones el autobiógrafo piensa, planea y organiza la información en los planos del sintagma y el paradigma. Esto se puede corroborar cuando se hace el guion, el story board y cuando se importan o descargan al proyecto audiovisual en el software de edición, los clips de video que se usarán en el montaje.

Aunque luego de esto, al ver el video se vea todo integrado y no sea posible una "lectura de la imagen videográfica" a la manera de un texto escrito, las coordenadas espacio temporales en las que simbolizamos y representamos nuestra vida, están allí implícitas o explícitas en las posibilidades y limitaciones de relatar nuestra existencia en cualquier lenguaje y medio.

La misma convención de encuadre y el diseño de la pantalla de edición son evidencias de que el plano cartesiano influye en la manera de pensar y de representar incluso por medio de la imagen. Sabemos que el cuadro en muchas pinturas, el encuadre en fotografia, cine, televisión, video y dispositivos móviles se rige en gran parte por la pirámide visual, con la que se representan en el plano cartesiano al menos tres dimensiones del espacio. 
Figura 5 - Tres dimensiones de la imagen figurativa en el espacio.

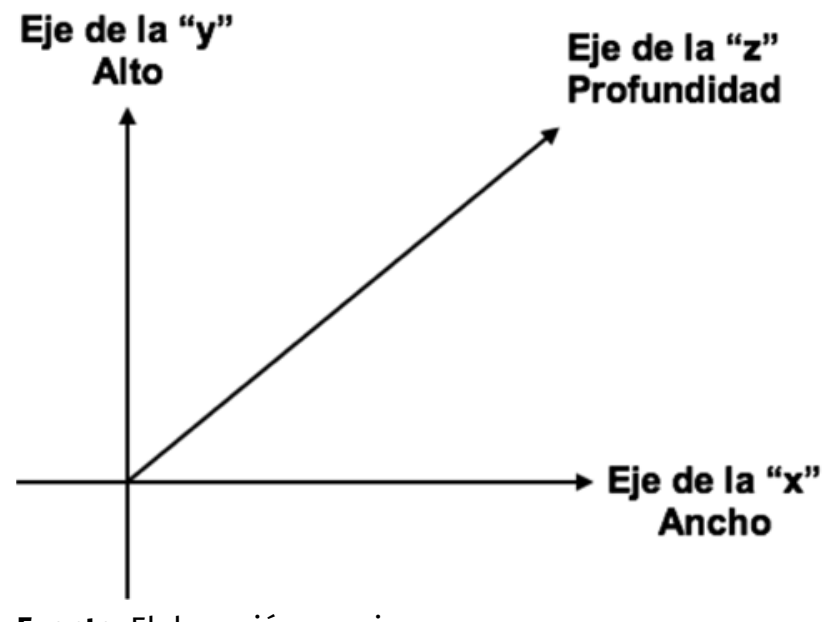

Fuente: Elaboración propia.

Esto tendrá relación con lo que piensa Thompson (2010), en relación con la experiencia cuando expresa que

La confiscación de la experiencia en coordenadas espacio-temporales de nuestra vida cotidiana corre paralela a la proliferación de la experiencia mediática y la mezcla rutinaria de experiencias que la mayoría de los individuos raramente hallarían en la experiencia cara a cara. (Ibid, p. 271)

Se trata pues de una experiencia mediatizada que nos provee de recursos para relatar, más allá de reproducir de manera oral un relato frente a una cámara, pues la experiencia mediática posibilita otras cosas que el encuentro cara a cara no permite.

El video autobiográfico permite otorgarle una cualidad al medio, que hace explícita su función en cuanto a que además de ser útil como soporte de memoria, y de servir para propósitos instrumentales, de reproducción, de documentación y archivo, nos da diversas opciones y recursos del lenguaje videográfico para relatar nuestra vida.

Entonces si el video es casero esa es su cualidad, si es artístico, musical, publicitario, periodístico, documental, etnográfico o biográfico, estos apellidos y cualidades del video determinan su función y a la vez las variacio- nes en la naturaleza de su lenguaje y de sus recursos expresivos, pero como se ha dicho el leguaje está vinculado no solo a nuestra experiencia y a nuestro modo de pensar, también a nuestra visión de mundo, a nuestra mirada.

El video autobiográfico es una forma de relatarse a sí mismo (MARÍN, 2010), que ha tomado de diversos medios y lenguajes un inventario de recursos para que el autobiógrafo se piense y se represente, de manera tal que explore su pensamiento audiovisual, su pensamiento videográfico como posibilidad de transformación de si mismo y de su existencia, como parte del poder que puede ejercer sobre su mundo y sobre su relato de vida, bien sea para concientizarse, para emanciparse, para cambiar o para conservar algo de sí o de otros, para establecer puntos de salida y de retorno en el diálogo consigo mismo, con otros y con el mundo, y para identificar aspectos de su proceso formativo que le permita tomar decisiones en todo sentido.

Con lo anterior, es importante decir lo que entiendo por relato autobiográfico. En clase digo a los estudiantes e investigadores, ${ }^{16}$ que autobiografía es un relato de un autobiógrafo que relata en primera persona, episodios y acontecimientos de su vida, y para ello usa los lenguajes y medios que le sean útiles para representarse a sí mismo.

En esta breve definición evito decir que se narra y prefiero decir que se relata por las razones que expuse con anterioridad.

Además hablo de autobiografía en el sentido en que lo explica Olney (2014), a partir de las tres dimensiones: autos, bios y graphe, ${ }^{17} \mathrm{de}$ autobiógrafo a partir de las distinciones que

16 En el Seminario Internacional de Investigación y Creación sobre Relato Autobiográfico y Competencia Mediática realizado como parte del proyecto en tres universidades (UTP, USP y UAB) como lo he mencionado páginas atrás.

17 Jesús Camarero (2011), usa el término grafein y Ángel Loureiro (1991), habla de grafé, pero los tres se refieren a lo mismo: el uso de lenguajes y medios para relatar. 
hace George Gusdorf (1991), pues considero que hablar de autor, narrador y personaje tiene otras consideraciones dramatúrgicas y literarias.

$Y$ distingo entre episodios y acontecimientos, pues encuentro tanto en Gusdorf (Ibid), $y$ en neurocientíficos como Antonio Damasio (2010), que la manera como damos relevancia a un evento en nuestra memoria, a partir el significado que le otorgamos cuando lo recordamos y cuando lo relatamos, determina el grado de importancia que para nosotros tiene un hecho y esto tiene implicaciones de todo orden.

\section{Experiencia de vida mediatizada ${ }^{18}$}

La experiencia entendida como los conocimientos y las habilidades que se desarrollamos y adquirimos está ligada a las vivencias, a la memoria y a los recuerdos que tenemos en el tiempo y en el espacio, pero también a los medios y los métodos utilizados para la educación. En este sentido se puede decir que la mirada es una de las cosas que se aprende y se modifica a lo largo de nuestra vida.

Ese aprendizaje lo podemos entender como Bruner y Olson (1973), en tres sentidos: uno, por experiencia contingente ya sea personal directa o dirigida por instrucción; dos, el aprendizaje por observación y modelos de instrucción; y tres los sistemas de símbolos utilizados para la comunicación y la instrucción. En estos dos últimos es importante el uso de los medios de comunicación, las imágenes y las pantallas, y en todos es importante la actuación como parte del proceso de aprendizaje.

Pero esta experiencia mediatizada en las sociedades contemporáneas acude cada vez a formas más complejas según Verón (1998), en las que los procesos de formación del yo se

18 He hecho distinciones entre lo que significa mediar y mediatizar en el artículo titulado La educación mediatizada. Distancias y aproximaciones en las metodologías de mediatización del conocimiento (MARIN, 2015). nutren de materiales mediáticos, experiencia confiscada en coordenadas espacio-temporales que antes estaban ligadas a lugares en los que la gente había vivido e interactuado con otras personas, y que ahora en nuevas formas de conocimiento no local, y otros tipos de material simbólico mediático, hacen que se enriquezca y se acentúe la organización reflexiva del yo, "el yo se vuelve cada vez más organizado como proyecto reflexivo a través del que el individuo construye, en forma de narrativa autobiográfica, un sentido de identidad propio" (THOMPSON, 2010, p. 278).

En ese sentido Anthony Giddens considera que: "Prácticamente toda experiencia humana es una experiencia mediada (por la socialización y, en especial, por la adquisición del lenguaje)" (GIDDENS, 1994, p. 37).

Se puede decir que la mediatización de la vida y de la experiencia en el relato autobiográfico, es un proceso en el que se ejerce el poder simbólico de representarse a sí mismo, cuando no son los medios los que lo hacen por medio de programas formateados para hacer de la vida íntima una mercancía, que en el contexto formativo este relato autobiográfico, se construye como conocimiento y acontecimiento, en marcos de referencia compartidos entre docentes y estudiantes, con el fin que por medio de la investigación-creación se trascienda a un nivel de conciencia histórica más elaborado, por lo que allí se da el proceso de mediación, y al tratarse de relatos en los que se aprende a usar diversos lenguajes y medios para representarse a sí mismo, el relato mediático toma forma según la naturaleza cultural, cognitiva y semiótica que descubrimos al expresarnos en primera persona.

Esto me lleva a plantear que las instancias mediadoras, las mediaciones y los medios de la autobiografía mediatizada, son elementos que hacen parte del desarrollo de habilidades reflexivas y expresivas, que permiten al au- 
tobiógrafo representarse a sí mismo y adquirir conciencia de sí, y de las posibilidades de transformación de nuestro propio mundo y el de otras personas.

Para explicar mejor esto propongo recurrir a Charles Sanders Peirce (1938-1956), para plantear estas instancias a partir de su idea de signo, constituido por un representamen, un objeto que se representa, y un interpretante que permite interpretar (que no es lo mismo que un intérprete o persona que interpreta).

Figura 6 - El signo según Charles Sanders Peirce.

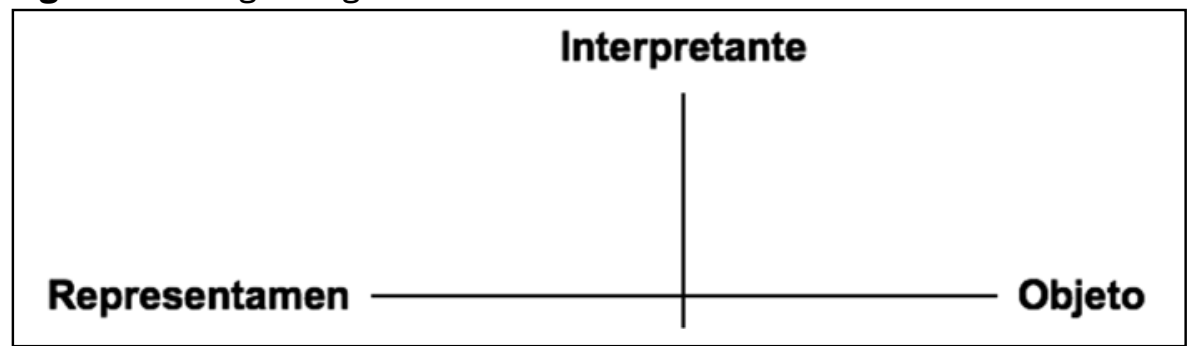

Fuente: Elaboración propia basado en los escritos de Peirce.

Estos elementos se pueden asociar a la ontología del signo de Peirce (primeridad, secundidad y terceridad) y a la ontología de la autobiografía de Olney (Ibid), donde la primeridad sería el graphe o medio técnico por el cual se relata, la secundidad el bios o el objeto del relato, y la terceridad el autos o la capacidad que adquiere y desarrolla el autobiógrafo de hacer conciencia histórica de sí, y de relatar su vida a la par que reflexiona.

Figura 7 - Ontología del signo según Charles Sanders Peirce.

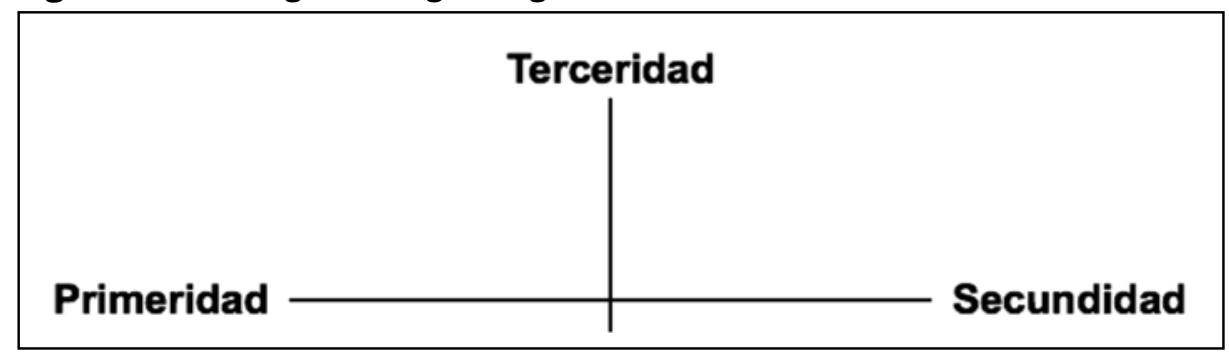

Fuente: Elaboración propia basado en los escritos de Peirce.

Cabe señalar que estos elementos son dinámicos y se interrelacionan, así el relato en su forma mediática en ocasiones media la comprensión de la vida del autobiógrafo, es decir que como lo dije en un texto anterior a este (MARÍN, 2016), el graphe está entre el autos (la autonomía y conciencia de sí), y el bios (su vida), y en otras ocasiones es el autos el que media la relación entre graphe y bios, en la medida que la conciencia de sí, se adquiere y desarrolla a la par que se construye el relato autobiográfico.
Figura 8 - Ontología de la autobiografía de James Olney en relación con la ontología del signo de Charles Sanders Peirce.

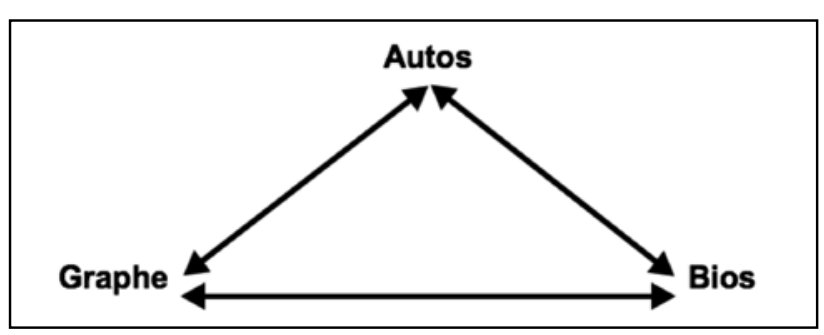

Fuente: Elaboración propia basado en Autobiography: Essays theoretical and critical de Olney ${ }^{19}$ y en los escritos de Peirce.

19 Cabe remitirnos a Jesús Camarero cuando señala el orden de importancia de las tres dimensiones: grafein, autos, bios, si tenemos en cuenta que se da "un nuevo nacimiento por mediación de la grafia" (CAMARERO, 2011, p. 37). 
Entonces habría que elaborar una concepción de mediación (auto)biográfica, teniendo en cuenta que pesquisadores como Conceiçao Passeggi (2011), y Souza (2011), han aportado elementos valiosos en este sentido.

Un modelo de esto que digo, tendría en cuenta que lo representado está mediado por la forma de representar que depende de los lenguajes y de los medios como primeridad (el graphe), como secundidad lo que se representa que depende de el enfoque y punto de vista del autobiógrafo (el bios, su vida en relación con...), y la representación mental, conceptual y activa como terceridad (el autos, el hacer el relato y relatarlo, narrarlo y argumentarlo).

Figura 9 - La representación de sí mismo en la autobiografía como parte del proceso de mediación (auto)biográfica.

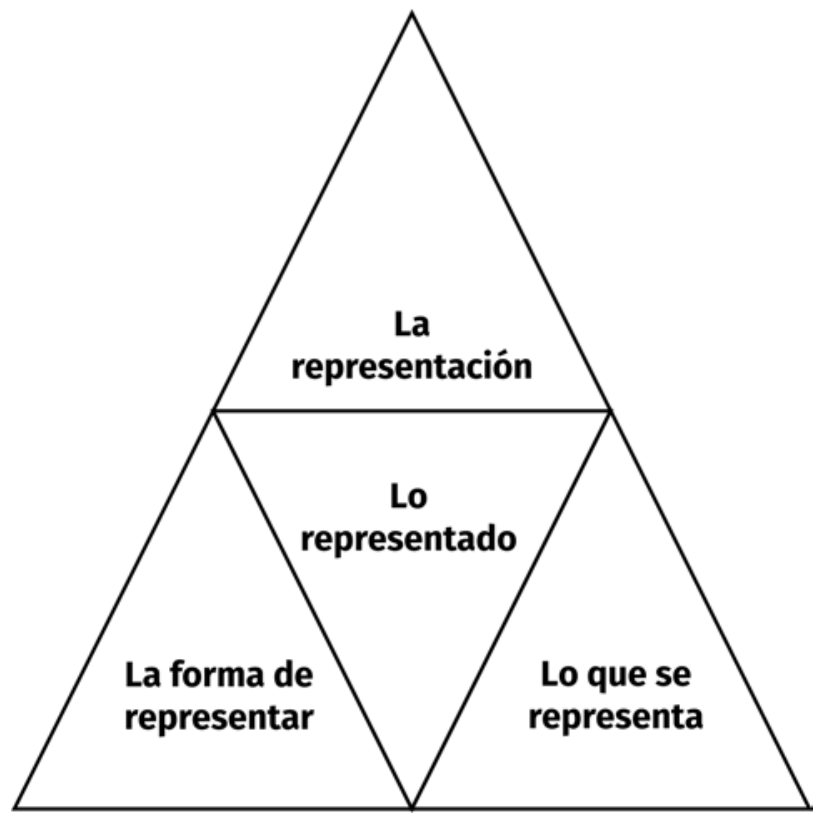

Fuente: elaboración propia.

Ahora bien, la invención de los medios de comunicación y nuestras relaciones con ellos y por medio de ellos han hecho que nuestra experiencia sea algo diferente en cuanto a la manera de comunicarnos, de representar nuestra realidad y la realidad del mundo a diferencia de las sociedades que nunca estuvieron o que no han estado aún en contacto con estos, por lo que requerimos de nuevos conocimientos y habilidades que nos permitan aprovechar y dominar las tecnologías de la información y de la comunicación, pues los medios y las TIC nos ponen ante la necesidad de desarrollar otro tipo de reflexividad y otros recursos expresivos, que modifican nuestra mirada, nuestra experiencia y nuestra existencia.

En este contexto ¿de qué manera el relato autobiográfico permite el desarrollo de una conciencia histórica reflexiva? Si nuestra historia tiene que ver con la manera como miramos al pasado, en retrospectiva, y actuamos en el presente con la perspectiva de futuro, y si el desarrollo de la conciencia está ligado al desarrollo del yo, podemos pensar que esa conciencia histórica de la que habla Olney (2014) se afianza por medio del relato autobiográfico, bien sea de forma oral, escrita, audiovisual 0 en cualquier otro medio y lenguaje. Lo que si hay que garantizar es que el autobiógrafo haga la reflexión, e indagar hasta dónde tiene conciencia de su relato en coordenadas articuladas a la historia de su familia, su barrio, su ciudad, su país y el mundo. Y proporcionarle una mirada ética, política, estética y dialógica para que se desenvuelva con otras personas como ciudadano del mundo.

\section{Referencias}

ARDÉVOL, Elisenda. Por una antropología de la mirada: etnografía, representación y construcción de datos audiovisuales. Revista de dialectología y tradiciones populares, Madrid, Instituto de Lengua, Literatura y Antropología, CSIC, Madrid, v. 53, n. 2, p. 217-240, 1998.

BOLIVAR, Antonio. Metodología de la investigación biográfico-narrativa: recogida y análisis de datos. En: PASSEGGI, Maria da Conceição; ABRAHÃO, Maria Helena. (Orgs.). Dimensões epistemológicas e metodológicas da pesquisa (auto)biográfica. Porto Alegre: EDIPUCRS, 2012, p. 79-109. 
BRUNER, Jerome; WEISSER, Susan. La invención del yo: la autobiografía y sus formas. En: OLSON, David; TORRANCE, Nancy. (Comps.). Cultura escrita y oralidad. Barcelona: Gedisa, 2013, p. 177-202.

BRUNER, Jerome. Realidad mental y mundos posibles. Los actos de la imaginación que dan sentido a la experiencia. Barcelona, España: Gedisa, 2010.

BUXÓ, María Jesús; DE MIGUEL, Jesús. (Eds.). De la investigación audiovisual: fotografía, cine, vídeo, televisión. Barcelona: Proyecto a ediciones, 1999.

CAJIAO, Francisco. Cosas, signos y lenguajes. Revista La alegría de Enseñar, Cali, Fundación FES, n. 32, p. 13-19, jul./sep. 1997.

CAMARERO, Jesús. Autobiografia y existencia. Barcelona: Anthropos Editorial, 2011.

SAUSSURE, Ferdinand de. Curso de lingüística general. 24 ed. Traducción de Amado Alonso. Buenos Aires: Editorial Losada, 1945.

DAMASIO, Antonio. Y el cerebro creó al hombre: ¿Cómo pudo el cerebro generar emociones, sentimientos, ideas y el yo? Barcelona: Destino, 2010.

GONZÁLEZ-MONTEAGUDO, José. La autobiografía educativa: formación, investigación y profesionalidad reflexiva. En: MORAES, Dislane Zerbinatti; LUGLI, Rosario Silvana. (Orgs.). Docência, pesquisa e aprendizagem: (auto)biografías como espaços de formação/investigação. São Paulo, Brasil: Cultura Acadêmica Editora, 2010. p. 69-85.

GUSDORF, George. Condiciones y límites de la autobiografía. Suplementos Anthropos, Barcelona, Editorial Anthropos, n. 29, p. 9-18, 1991.

LOUREIRO, Ángel G. (Coord.). Introducción. La autobiografía y sus problemas teóricos. Estudios e investigación documental. Revista Anthropos, Barcelona, Editorial Anthropos, n. 29, p. 2-9, 1991.

MARÍN OSSA, Diego Leandro. Videoexpresión. Una invención de sí mismo. Pereira: Universidad Tecnológica de Pereira, 2010.

MARÍN OSSA, Diego Leandro. La educación mediatizada. Distancias y aproximaciones conceptuales en las metodologías de mediatización del conocimiento. Revista da FAEEBA - Educação e Contemporaneidade, Salvador, Universidade do Estado da Bahia, v. 24, n. 44, p. 41-53, jul./dez. 2015.

MARÍN OSSA, Diego Leandro. Autobiografia, imágenes y pantallas. El aprendizaje del autodescubrimiento por experiencia mediatizada. En: MORAES, Dislane Zerbinatti; CORDEIRO, Verbena Maria Rocha; OLIVEIRA, Ozerina Victor de. (Orgs.). Narrativas digitais, história, literatura e artes na pesquisa (auto) biográfica. Curitiba: Editora CRV, 2016. p. 29-48.

NICHOLS, Bill. La representación de la realidad: cuestiones y conceptos sobre el documental. Barcelona: Paidós, 1997.

OLNEY, James. Autobiography: essays theoretical and critical. New Jersey: Princeton University Press, 2014.

PEIRCE, C. S. The collected papers, 8 vols. Cambridge: Harvard University Press, 1938-1956.

PASSEGGI, María da Conceição. Aproximaciones teóricas a las perspectivas de la investigación (auto) biográfica en educación. Revista Educación y Pedagogia, Medellín, Universidad de Antioquia, v. 23, n. 61, p. 25-40, 2011.

SILVA VALLEJO, Fabio. (Comp.). Las voces del tiempo: oralidad y cultura popular. Santa Fe de Bogotá: Arango Editores, 1997.

SOUZA, Elizeu Clementino de. Acompañamiento, mediación biográfica y formación de formadores: dimensiones de investigación-formación. Revista Educación y Pedagogía, Medellín, Universidad de Antioquia, v. 23, n. 61, p. 41-56, sept./dez. 2011.

VÁSQUEZ RODRIGUEZ, Fernando. Más allá del ver está el mirar (pistas para una semiótica de la mirada). Signo y Pensamiento, Santa Fe de Bogotá, Pontificia Universidad Javeriana, v. 11, n. 20, p. 31- 40, abr. 1992.

Recebido em: 06.01.2018 Aprovado em: 10.03.2018 
Diego Leandro Marín Ossa Doctorando en Comunicación y Periodismo en la línea de Alfabetización Mediática e Informacional, de la Universidad Autónoma de Barcelona (UAB). Magister en comunicación educativa. Docente investigador de la Universidad Tecnológica de Pereira (UTP), Colombia, en el área de medios y educación de la Escuela de Español y Comunicación Audiovisual. Director del grupo y semillero de investigación Edumedia-3 UTP. Integrante del Gabinete de Comunicación y Educación UAB. Email: leandro73@utp.edu.co

Carrera 27 \#10-02 Barrio Los Álamos - Pereira, Risaralda - Colombia. Tel: +57 63137234 